\section{Diabetic retinopathy: major unmet medical challenge}

\author{
Joanna M. Tarr, Kirti Kaul, Eva M. Kohner, \\ Rakesh Chibber
}

Institute of Biomedical and Clinical

Science, Peninsula College of Medicine and Dentistry, University of Exeter, UK

\begin{abstract}
Since diabetes is now a global epidemic, the incidence of retinopathy, a leading cause of blindness in patients aged 20 to 74 years, is also expected to rise to alarming levels. The risk of development and progression of diabetic retinopathy is closely associated with the type and duration of diabetes, blood glucose, blood pressure and possibly lipids. It is an unmet medical need that can lead to severe and irreversible loss of vision in people of working age worldwide. The aim of this review is to give an overview of the clinical and anatomical changes during the progression of retinopathy, the underlying pathogenic mechanisms that link hyperglycaemia with retinal tissue damage, current treatments and the emerging pharmacological therapies for this sight-threatening complication of diabetes.
\end{abstract}

\section{Introduction}

Diabetes is now a global epidemic with recent surveys predicting that by 2025 , the number of patients with diabetes will rise to staggering 380 million.1,2 This diabetes epidemic will lead to the increasing incidence of the two major types of long-term complications: macro vascular and micro vascular that contribute to morbidity and premature deaths. The macro vascular complications which affect the large vessels include cardiovascular, cerebrovascular and peripheral vascular disease. The micro vascular complications which affect the small vessels include neuropathy, nephropathy, and retinopathy. Diabetic retinopathy is one of the fastest growing causes of blindness and visual impairment in the working age population.

\section{Sign and symptoms}

Most diabetic patients may not experience any warning symptoms during the early stage of diabetic retinopathy. However, signs that may suggest the need for an urgent consulta- tion with an eye care professional include blurred or sudden loss of vision and the presence of floaters and flashes.

\section{Methods of examination}

Early detection of diabetic retinopathy can prevent severe loss of vision and blindness. Diagnosis of diabetic retinopathy involves visual acuity tests, fundus examination (direct and indirect ophthalmoscopy) and retinal photography. Optical coherence tomography (OCT) examines the major layers of the retina with different reflectance of visible light. The technique is able to localise retinal lesions in relation to different retinal layers and quantify the retinal thickness. OCT can also be used to diagnose retinal oedema and measure retinal blood flow. ${ }^{3}$

\section{Classification, clinical features and anatomical changes}

According to the International Clinical Diabetic Retinopathy Scale, ${ }^{4}$ retinopathy progresses from no retinopathy, nonproliferative diabetic retinopathy (NPDR) and proliferative diabetic retinopathy (PDR) (Figure 1). This progression involves various clinical signs (Figure 2A) that include the formation of microaneurysms, dot and blot retinal haemorrhages, hard exudates, cotton wool spots, venous abnormalities, and the growth of new blood vessels. ${ }^{5}$

NPDR is graded as mild, moderate, and severe (Figure 2B) according to the presence of these lesions. PDR (Figure $2 \mathrm{C}$ ) involves the growth of new blood vessels in response to retinal ischaemia. These new vessels can develop from the disc (neovascularisation of the disc, NVD) or from elsewhere in the retina (neovascularisation elsewhere, NVE).

Along with PDR, diabetic macular oedema (DM0) is a major cause of severe visual impairment in patients with diabetes. DMO (Figure 2D) can develop in NPDR and PDR and it is caused by leakage and build-up of fluid and proteins within 2 disc diameters of the macular region. The three types of diabetic maculopathy include exudative (focal), oedematous (diffuse or cystoid) and ischaemic. Focal exudative maculopathy is characterised by hard exudates present in a circinate pattern, with microvascular abnormalities (microaneurysms, haemorrhages) in the centre of the rings. Oedematous (diffuse, focal or cystoid) maculopathy is characterised by fluid accumulation in the perifoveal area and may result in cyst formation. Ischaemic maculopa-
Correspondence: Rakesh Chibber, Institute of Biomedical \& Clinical Science, Peninsula College of Medicine and Dentistry, Universities of Exeter \& Plymouth, St Luke's Campus, Magdalen Road, Exeter, EX1 2LU, UK.

Tel: +44.0.1392 262934.

E-mail: rakesh.chibber@pms.ac.uk

Key words: diabetic retinopathy, diabetic maculopathy, emerging therapeutic targets, management.

Acknowledgements: the authors would like to thank Professor Toke Bek (Department of Ophthalmology, Aarhus University Hospital, DK8000 Aarhus C, Denmark) for kindly providing fundus photograph presented in Figure 2A. The other photographs are reproduced with permission from "Diabetic Retinopathy: Diagnosis, Management and Reference Images" CD 0 (www.ramex.com)

Received for publication: 10 June 2011.

Accepted for publication: 22 June 2011.

This work is licensed under a Creative Commons Attribution NonCommercial 3.0 License (CC BYNC 3.0)

(C) Copyright J.M. Tarr et al., 2011 Licensee PAGEPress, Italy

Endocrinology Studies 2011; 1:e7

doi:10.4081/es.2011.e7

thy is characterised by enlargement of the perifoveal due to capillary closure and results in marked visual loss with microaneurysms, haemorrhages, mild or no intracellular macular oedema and a few hard exudates.

If PDR is left untreated it eventually leads to advanced diabetic eye disease (Figure 2E). Advanced diabetic eye disease is characterised by vitreous haemorrhages, tractional retinal detachments, glaucoma and rubeosis iridis and eventually leads to complete blindness.

The anatomical changes that occur during diabetic retinopathy have been well characterised and include the loss of pericytes and endothelial cells, formation of acellular capillaries, early thickening of the basement membrane, formation of microaneurysms and retinal neovascularisation. ${ }^{6}$

\section{Epidemology and risk factors}

According to the World Health Organization (WHO) diabetic retinopathy is responsible for $4.8 \%$ of the 37 million cases of blindness worldwide. ${ }^{7}$ The results from various epidemiological clinical studies including the Wisconsin Epidemiological Study on Diabetic Retinopathy 
(WESDR), Diabetic Retinopathy Study (DRS), Early Treatment of Diabetic Retinopathy Study (ETDRS), Diabetes Control and Complications Trial (DCCT), Diabetic Retinopathy Vitrectomy Study (DRVS), UK Prospective Diabetes Study (UKPDS) have identified various risk factors for understanding the development and progression of diabetic retinopathy.-13

The major risk factors for diabetic retinopathy are hyperglycaemia, high blood pressure, and duration of diabetes. A number of studies have confirmed the pathogenic link between hyperglycaemia and the onset and progression of diabetic retinopathy. The DCCT and UKPDS provided conclusive evidence that tight control of blood glucose can delay the onset and progression of diabetic retinopathy in patients with type 1 and type 2 diabetes, respectively. ${ }^{11,14}$ However, if blood glucose is rapidly controlled in patients with previous poor control, it can worsen diabetic retinopathy. ${ }^{15}$

The duration of diabetes is an important risk factor for diabetic retinopathy. In patients with type 1 diabetes, the incidence of retinopathy in the first $3-5$ years is very rare, but thereafter there is a rapid rise, so that by 20 years over $90-95 \%$ of patients have some degree of retinopathy. 16,17 PDR in this group of patients is almost always absent for the first 10 years, again with a rapid rise to $60 \%$ by 20 years of duration. In comparison, $60-70 \%$ of the
No apparent Retinopathy

Normal retina and no retinal abnormalities

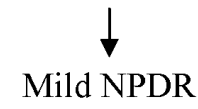

Presence of at least one microaneurysm

\section{Moderate NPDR}

Presence of hemorrhages, microaneurysms, and hard exudates, cotton wool spots, venous beading, and IRMA.

Less than that seen in severe NPDR<smiles>C[13CH2]</smiles>

Severe NPDR (Fig 2B)

Characterised by numerous microaneurysms and more than 20 intraretinal haemorrhages in each of 4 quadrants, definite venous beading in $2+$ quadrants and Prominent intraretinal microvascular abnormalities (IRMA) in 1+ quadrant.

No signs of PDR

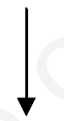

PDR (Fig 2C)

New vessels at the optic disc, new vessels elsewhere and preretinal or vitreous hemorrhage

Figure 1. Natural progression of diabetic retinopathy according to the International Clinical Diabetic Retinopathy (DR) Disease Severity Scale.

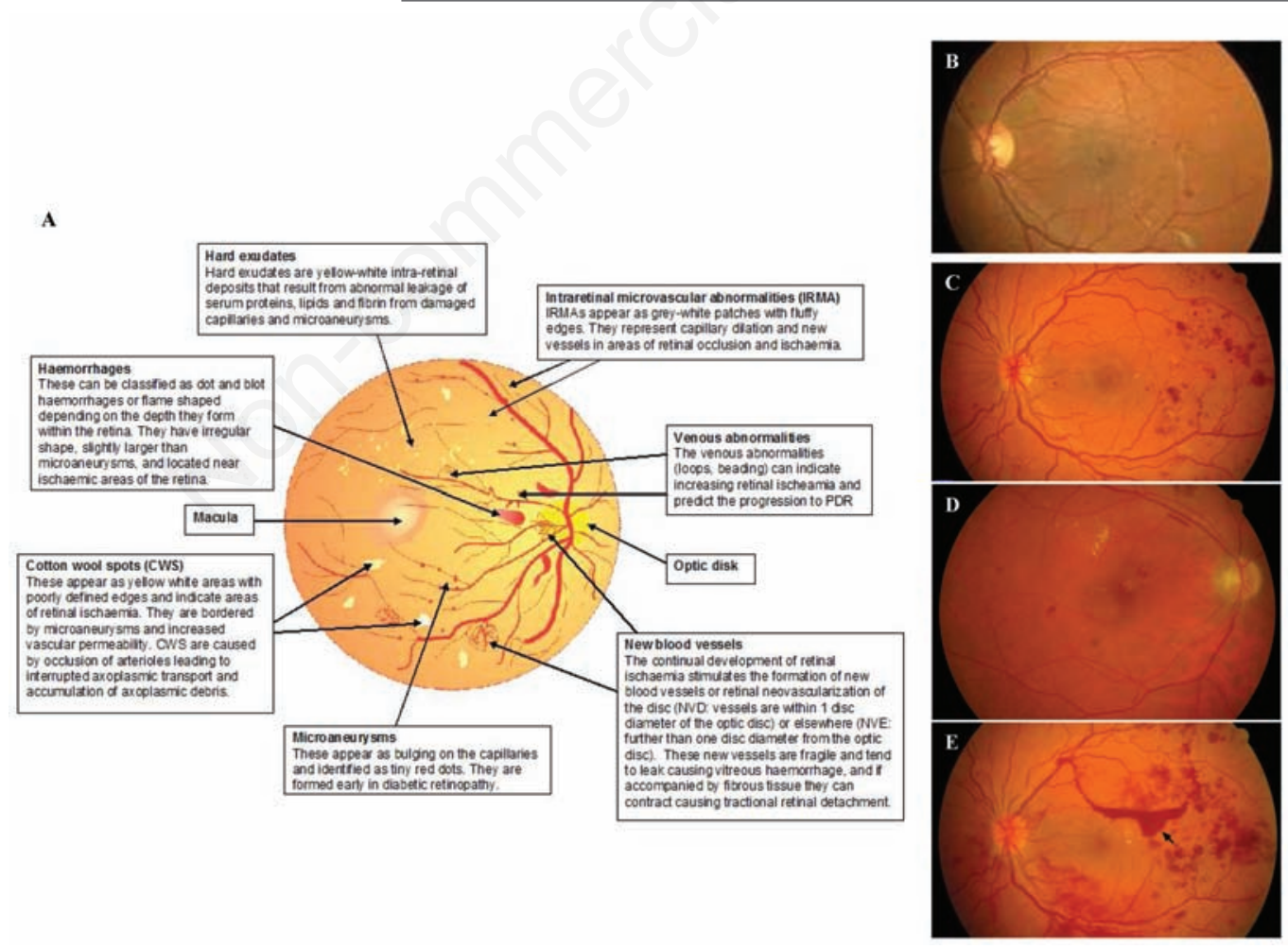

Figure 2. Diabetic retinopathy. (A) Schematic diagram defining the retinal lesions in diabetic retinopathy. (B) Fundus photograph showing severe non-proliferative (NPDR) diabetic retinopathy: microaneurysms, venous abnormalities, intraretinal microvascular abnormalities, cotton wool spots and hemorrhages. (C) Proliferative diabetic retinopathy: New vessels are present at the optic with blot haemorrhages in the macular area. (D) Diabetic retinopathy with exudative maculopathy showing hard exudates. (E) Advanced eye disease. New vessel on the optic disk, blot haemorrhages, and preretinal haemorrhage (arrow). Hard exudates are present near the fovea indicate the presence of clinically significant macular oedema (DMO). 
patients with type 2 diabetes will have some retinopathy after 20 years. ${ }^{14,18}$ In the long term, patients with type 2 diabetes have a much higher risk of developing DMO than PDR. The prevalence of DM0 after 15 years of diabetes is approximately $20 \%$ and $25 \%$ in patients with type 1 and type diabetes, respectively. ${ }^{19}$

Studies like the WESDR and the UKPDS have established that blood pressure is a predictor of the progression of PDR in type 1 and type 2 diabetes respectively, and that this progression is independent of glycaemic control and proteinuria. ${ }^{20,21}$

Other risk factors for diabetic retinopathy include age at onset of diabetes, hyperlipidaemia, gender, ethnicity, cataract extraction, puberty and pregnancy.8,9,22-24 Genetics may also be involved since some patients with long duration of diabetes fail to develop diabetic retinopathy, while some patients may still show rapid progression of diabetic retinopathy despite tight blood glucose control.25,26

\section{Current management and treatment}

Tight control of blood glucose, blood pressure and possibly lipids are important management strategies to reduce the onset and progression of diabetic retinopathy.

The uses of anti-hypertensive drugs such as angiotensin converting enzyme (ACE) inhibitors were investigated by several groups. The EURODIAB Controlled Trial of Lisionpril in Insulin-Dependent Diabetes Mellitus (EUCLID) study group found the ACE inhibitor, lisonopril, reduced the progression of diabetic retinopathy by $50 \%$ and the progression of PDR by $82 \%$ in normotensive type 1 diabetes patients. ${ }^{27}$ This can be interpreted as the involvement of a cellular role of the reninangiotensin system (RAS) pathway that contributes to pathogenesis in the retinal tissue independent of blood pressure.

The Action in Diabetes and Vascular Disease Controlled Evaluation Retinal Measurement (ADVANCE-ADREM) study lso investigated the effect of the ACE inhibitor perindopril and indapamide in type 2 diabetes patients. ${ }^{28}$ While the ACE inhibitors had some effect in reducing the progression of retinopathy, this number was considerably different from the EUCLID study. This disparity maybe a result of the difference in the patient cohort of the two studies, since all patients in EUCLID were normotensive.

Clinically it is difficult to achieve and maintain near normal levels of glucose and blood pressure, and laser photocoagulation and possibly vitrectomy may be needed to reduce the risk of severe visual loss from sight threatening diabetic retinopathy. Laser photocoagula- tion with argon green laser is effective for PDR and diabetic maculopathy. ${ }^{29}$ Vitrectomy may be indicated for PDR and advanced diabetic eye disease with severe visual loss. ${ }^{30}$

\section{Pathogenesis}

Surgical management with laser surgery and vitrectomy is effective in reducing vision loss and useful for late stage of retinopathy, but it is devastating. The continual growing understanding of the pathogenesis of diabetic retinopathy is helping to facilitate new and early treatments and preventive strategies.

The DCCT and UKPDS clinical trials confirmed the role of chronic hyperglycaemia in diabetic retinopathy, but the underlying mechanism of how glucose causes microvascular damage remains unknown. Research worldwide has established various biochemical mechanisms that potentially link hyperglycaemia and diabetic retinopathy. These proposed and tested mechanisms include polyol pathway flux, activation of diacylglycerol (DAG)-PKC pathway, increased expression of growth factors (vascular endothelial growth factor, VEGF; insulin-like growth factor-1, IGF1), accelerated formation of advanced glycation end products (AGEs), oxidative stress, haemodynamic or retinal blood flow changes, activation of the RAS pathway and sub-clinical inflammation. ${ }^{31}$

\section{Polyol pathway}

In cellular glucose metabolism a small percentage of glucose is metabolised through the polyol pathway. In diabetes, the flux of glucose through this pathway increases. The polyol pathway is controlled by two enzymes. The first enzyme, aldose reductase (AR) using nicotinamide adenine dinucleotide phosphate (NADPH) reduces glucose to sorbitol, which is then converted to fructose by the second enzyme, sorbitol dehydrogenase (SDH). The excessive build-up of sorbitol in cells is thought to cause osmotic damage to the retinal vascular cells leading to diabetic retinopathy. ${ }^{32}$ Genetic polymorphism studies suggest a link between AR and diabetic retinopathy. ${ }^{33}$ However, the role of AR in diabetic retinopathy remains controversial. ${ }^{34-36}$ There is some evidence suggesting a more important link between SDH and diabetic retinopathy than AR. 37,38

\section{Non-enzymatic glycation}

Glycation is a chemical reaction in which glucose binds to proteins and lipids leading first to the formation of the Schiff's bases, then Amadori products and finally, after slow and complex rearrangements, to irreversible
AGEs. ${ }^{39,40}$ The accelerated accumulation of AGEs in diabetes can cause cross-linking of long-lived proteins leading to stiffness and vascular dysfunction. In addition, the binding of AGEs with specific cell surface AGE receptors including the receptor for advanced glycation end product (RAGE), can induce intracellular signaling, oxidative stress and the production of key pro-inflammatory and pro-sclerotic cytokines. $^{41}$ Several studies indicate that serum AGE levels are associated with incidence of diabetic retinopathy amongst other vasculopathies. ${ }^{42}$

Prevention of AGE formation using aminoguanidine (pimagedine) has been shown to prevent retinopathy-like changes (pericyte loss and acellular capillaries) in diabetic rats. ${ }^{43}$ Although the significance of AGEs and their inhibition can be appreciated based on experimental diabetes, there is limited information available supporting the clinical application of these agents in the development and progression of diabetic retinopathy. Furthermore, the use of aminoguanidine is associated with adverse effects that arise from an imbalance of the vitamin B6 metabolism and side effects related to the kidneys, the gastrointestinal tract and the liver. ${ }^{44}$

\section{Protein kinase $C \beta 1 / 2$}

In diabetes, glucose-induced activation of protein kinase $\mathrm{C}$ beta $1 / 2(\mathrm{PKC} \beta 1 / 2)$ via DAG leads to changes in endothelial permeability, contractility, extracellular matrix protein synthesis, haemodynamics (retinal blood flow) changes, production and intracellular signalling of VEGF. 45,46 Glucose induced PKC $\beta 1 / 2$ activation is also thought to contribute to the loss of capillary pericytes. 47

\section{Inflammation}

Recent clinical research indicates the impact of sub-clinical inflammation in the development and progression of diabetic complications. ${ }^{8}$ Increase in serum concentrations of pro-inflammatory cytokines, adhesion molecules and activation of immune cells together contribute to an enhanced inflammatory response. In the retinal vasculature this leads in leukostasis and increased vascular permeability via VEGF, important early features of diabetic retinopathy. The extent of leukostasis, which in turn leads to capillary occlusion and non-perfusion, greatly influences the prognosis in diabetic retinopathy. ${ }^{49}$

\section{Haemodynamics changes}

Loss of autoregulation and increased retinal blood flow has been suggested as a potential mechanism in the onset and progression of diabetic retinopathy. ${ }^{50-52}$ In contrast, other groups have reported reduced retinal blood flow or no significant change in diabetes. ${ }^{53-56}$ 


\section{Growth factors}

The insulin like growth factors (IGF) are synthesised by almost all tissues in the body and are mediators of cell growth, differentiation and transformation. Elevated vitreous and serum levels of IGF-1 in patients with PDR have led to investigations into the role of the growth hormone and IGF axis in retinopathy pathogenesis. The exact role of IGF-1 in diabetic retinopathy pathogenesis remains unclear. ${ }^{57-60}$

VEGF is a heparin-affin growth factor which exists in four homodimeric molecular species, each monomer having respectively 121, 165, 189 or 206 amino acids. VEGF via its interaction with flt-1 and KDR receptors plays a key role in angiogenesis and vascular permeability. Studies over many years have implicated VEGF, particularly the 165 isoform, in the development of both PDR and DM0.61,62 VEGF levels are higher in patients with diabetic retinopathy and the levels have been shown to decrease after laser therapy. 63,64

Blocking VEGF prevents development of proliferative disease in an oxygen-induced retinopathy (OIR) mouse model.65 Injection of VEGF165 into the vitreous of healthy primates leads to the formation of microaneurysms, hemorrhage, capillary closure, vascular leakage, and retinal angiogenesis.

\section{Oxidative stress}

Oxidative stress is the imbalance between the production of reactive oxygen species (ROS) and the cells ability to remove or neutralise the ROS using anti-oxidants. Oxidative stress results in damage to cellular components and contributes to the pathogenesis of certain diseases. It is now established that diabetes is associated with increased production of ROS such as the superoxide anion and a decrease in the level of antioxidant enzymes.66,67 The production of ROS is thought to lead to the activation of several other detrimental pathways such as the PKC $\beta 1 / 2$, and hexosamine pathways and the formation of AGEs. ${ }^{68,69}$

\section{Renin angiotensin system}

The renin-angiotensin system (RAS) is the hormone system which regulates blood pressure and fluid balance. The RAS system has been shown to be disturbed in patients with diabetes..$^{70}$ It has been demonstrated that in the retina all components of the RAS system are expressed including renin, ACE, ACE2 and angiotensin type 1 and 2 receptors.71,72 Increased ACE expression in the retina has been shown to have adverse effects on the retinal vasculature which are independent of systemic blood pressure. ${ }^{33}$ Furthermore, in animal models of retinopathy, treatment with the ACE inhibitor lisinopril or the angiotensisn II type 1 receptor blocker losartan can inhibit new blood vessel formation. ${ }^{74}$

\section{Emerging treatments}

Inhibition of some of the biochemical mechanisms linking hyperglycaemia and diabetic retinopathy has produced encouraging results in animal and/or clinical patients. The drugs tested include inhibitors of aldose reductase, oral protein kinase $\mathrm{C} \beta 2 / 1$ inhibitor, somatostatin analogs, anti-VEGF agents, angiotensin receptor blocker (ARB), anti-inflammatory drugs and hyaluronidase.

\section{Aldose reductase inhibitors}

Although clinical trials have failed to confirm therapeutic potential of AR inhibitors (ARIs) in diabetic retinopathy, new and more effective ARIs are being developed. $.55-77$

\section{Protein kinase $C \beta 2 / 1$ inhibitor}

Ruboxistaurin mesylate (Arxxant, Eli Lilly, Indianapolis, USA), a specific inhibitor of $\operatorname{PKC} \beta 1 / 2$, was developed and tested for the treatment of diabetic retinopathy. In animal studies, ruboxistaurin delayed the progression of diabetic retinopathy.78,79 Encouraging animal data led to two multi-centre, placebo-controlled, phase 3 clinical trials of ruboxistaurin: the PKC DR study (PKC-DRS) and the diabetic Macular Edema Study (PKC-DMES). ${ }^{80,81}$ The PKC-DRS trial reported that ruboxistaurin did not prevent the progression of diabetic retinopathy or the need for laser photocoagulation, but significantly reduced the occurrence of sustained moderate visual loss. This effect was greatly influenced by the extent of glycaemic control, such that in patients with HbAlc $\geq 10$, the effect of ruboxistaurin was more pronounced and clinically significant. ${ }^{80}$ In the PKC-DMES trial, ruboxistaurin was found to significantly reduce the progression to DMO. 81

PKC-DRS2 a multi-centre, 36-month, placebo-controlled, phase III clinical trial reported the potential of ruboxistaurin to reduce sustained moderate visual loss by $40 \%$ after 3 years. ${ }^{82}$ Although ruboxistaurin is a well tolerated drug with few significant adverse effects which has shown some clinical effectiveness, it is not available as a therapy for diabetic retinopathy.

\section{Anti-inflammatory drugs}

Early pre-clinical work on the effect of salicylates was effective in reducing TNF- $\alpha$ levels, the activation of NF-KB in the retina and consequently leukostasis. 83,84 Although, aspirin did not translate as an effective drug in the prevention of diabetic retinopathy in clinical trials, these studies did conclude that aspirin bears no contraindication in the management of coronary vascular diseases (CVDs), in the presence of retinopathy. ${ }^{85,86}$
Intravitreal injection of the corticosteroid triamcinolone acetonide (IVTA; enalog, Bristol-Myers Squibb), with potential to reduce inflammation, vascular leakage and VEGF expression have shown a reduction in macular thickness, and improved visual acuity in patients with DM0.87-89 A follow up study also showed that over a period of 3 years, while IVTA reduces the risk of progression of retinopathy, it presents a risk of cataract formation, glaucoma, endophthalmitis and pseudoendophthalmitis, and that focal/grid photocoagulation is more effective than IVTA in managing DMO.$^{89,90}$ It must be noted that although these anti-inflammatory treatments are less invasive than surgery, they can introduce complications due to their mode of delivery. As a result, there is great impetus in the development of topically administered drugs such as nepafenac, a non-steriodal antiinflammatory drug observed to significantly reduce pericyte loss, and leukostasis in animal models of diabetic retinopathy. ${ }^{91}$ Nepafenac has demonstrated some beneficial effect in patients with DM0.92

In addition, there is ongoing interest in developing sustained-release or biodegradable intraocular implants with the aim of delivering active steroids for a much longer time. Recent studies have focussed on the use of a dexamethasone implant and fluocinolone for the treatment of DMO. ${ }^{89,93}$

Recent development of topical anti-TNF- $\alpha$ is also a crucial advance. ESBA105 is a single chain antibody fragment that can be administered topically, and has been tested in animal models for its effect on choroidal neovascularisation. ${ }^{44}$ The drug is yet to be tested in a clinical setting.

Another class of drug, Infliximab (ScheringPlough, New Jersey, USA), an antibody that antagonises TNF- $\alpha$ has proven to be successful in improving visual acuity and reducing macular thickness. ${ }^{95}$ These encouraging results need further substantiation with Phase IV trials and assessment of adverse effects over longer periods of treatment.

\section{Fenofibrate}

Fenofibrate is a lipid-regulating drug commonly used for the treatment of hyperlipidaemia. Beyond its lipid lowering effects, the recent Fenofibrate Intervention and Event Lowering in Diabetes (FIELD) trial found that patients with type 2 diabetes receiving fenofibrate required less photocoagulation for PDR and DM0.96 The Action to Control Cardiovascular Risk in Diabetes (ACCORD) Eye study showed that treatment of type 2 diabetic patients with fenofibrate in combination with simvastin was able to reduce the odds of having progression of retinopathy by $40 \%$ over 4 years compared to treatment with simvastin alone. ${ }^{97}$ Further work is still needed to under- 
stand the underlying mechanism by which fenofibrate has a positive affect in DR and DM0. A number of potential mechanisms have been proposed which include: inhibition of the VEGF pathway, reduction in the levels of proinflammatory cytokines and adhesion molecules and sustained activation of the AMP-activated protein kinase pathway. 98

\section{Somatostatin analogues}

Somatostatin is an endogenous polypeptide hormone of 14 or 28 aminoacids with potent anti-angiogenic properties. The somatostatin analogue octreotide has proved beneficial in preventing the progression to high-risk PDR, haemorrhage and the requirement for photocoagulation and vitrectomy. ${ }^{99-102}$ No adverse side effects have been found with octreotide treatment in these studies. It has been hypothesised that the effects of octreotide are due to the direct neuroprotective and anti-angiogenic effects rather than its ability to indirectly lower IGF-1.103 From the current studies it appears that treatment with ocreotide is beneficial in severe NPDR and PDR, although further greater powered studies are required to confirm this. Current efforts are focusing on the development of improved somatostatin analogues with increased selectivity. ${ }^{104}$

\section{Anti-VEGF agents}

Currently, pegaptanib, bevacizumab, ranibizumab and VEGF trap are being tested for the potential treatment of diabetic retinopathy. Recent evidence from clinical trials suggests beneficial effect of anti-VEGF agents in DMO and PDR. ${ }^{105-110}$ In DMO VEGFtrap was shown to have clinically significant improvement on the visual acuitity of patients compared to photocoagulation. ${ }^{111,112}$

Recently the use of intravitreal bevacizumab as a pre-operative adjunctive therapy for vitrectomy patients has been investigated. Promising results have demonstrated pretreatment with bevacizumab accelerates vitreous clear up, reduces intraoperative bleeding, post operative hemorrhages and active neovascularisation. 113,114

Despite promising results with anti-VEGF therapy, there are questions regarding its longterm safety in patients and repeated intravitreal injections may be associated with sideeffects such as uveitis, cataract, retinal detachment, and endophthalmitis. ${ }^{62,112}$ Reducing VEGF levels in mice was found to cause death of photoreceptors and Muller glia involved required for normal visual function. ${ }^{115}$

\section{Angiotensin receptor blocker}

In light of the success of ACE inhibitors in the treatment of DR, other approaches to target the RAS pathway such as angiotensin receptor blockers (ARBs) have also been con- sidered.116 The DIabetic REtinopathy Candesartan Trials (DIRECT), a large multicentre trial, consisted of three arms; the DIRECT- Prevent 1, DIRECT-Protect 1 and DIRECT-Protect 2.117,118 The first two groups determined whether ARB blocker candesartan prevented the incidence and progression of retinopathy in type 1 patients, while the third group investigated the effect of the drug on the progression of retinopathy in type 2 patients. Findings demonstrated significant reduction in the incidence of retinopathy in patients with type 1 diabetes, and the progression of retinopathy in patients with type 1 and type 2 diabetes. However, it is unclear if the beneficial effect was via RAS blockade, or lowering of blood pressure.

More recently, the RAS Study trial (RASS) has investigated the effect of ACE inhibitor enalapril against ARB losartan in normotensive patients to elucidate the mechanism of protection/prevention against retinopathy, and whether it is indeed independent of hypertension. ${ }^{119}$ Although, the ACE inhibitor was effective in reducing the progression of retinopathy, losartan was more potent in exerting this effect. This study highlighted the significance of RAS blockade in patients with NPDR or early stages of retinopathy, and can offer a novel approach to diabetes management and prevention of retinopathy in the future.

\section{Antioxidants}

A small number of studies on the effects of antioxidants on diabetic retinopathy have been performed; however whether the treatment is beneficial remains controversial. A small study demonstrated that diabetic patients with little or no diabetic retinopathy had a reversal in blood flow abnormalities after treatment with a high-dose of vitamin-E. ${ }^{120}$ Recently a 5 year follow up study indicated that antioxidant supplementation was able to cause retardation in the progression of retinopathy compared to a control group. ${ }^{121}$ However, two other clinical trials have shown that vitamin $\mathrm{C}$ and $\mathrm{E}$ treatment had no benefit on diabetic retinopathy. ${ }^{122}$ Further work needs to be performed to ascertain whether antioxidant treatment is a viable therapy for diabetic retinopathy.

\section{Inhibitor of carbonic anhydrase}

A recent study has introduced carbonic anhydrases, an enzyme that converts carbon dioxide to bicarbonate and protons, in the pathogenesis of diabetic retinopathy. ${ }^{123}$ The finding that inhibition of carbonic anhydrase prevents retinal vascular permeability in an animal model of diabetes suggests this enzyme as a potential therapeutic target in diabetic retinopathy.

\section{Enzymatic vitreolysis}

A recent addition to vitrectomy has been enzymatic vitreolysis to clear vitreous haemorrhage. ${ }^{124}$ Intravitreous ovine hyaluronidase (Vitrase; ISTA Pharmaceuticals, Inc., CA, USA) has been tested and shown to be effective in the management of persistent vitreous haemorrhage from PDR. ${ }^{125,126}$ Other potential vitreolysis enzymes include plasmin, and microplasmin. ${ }^{127}$

\section{Combination therapy}

Based on the comprehensive information and investigations over the years that target pathways in the prevention and protection against diabetic retinopathy, it has become evident that there is no one magic bullet and combination therapies may pave the way for a novel and more effective approach to the management and treatment of diabetic retinopathy. The combination of triamcinolone and the anti-VEGF agent, bevacizumab, has shown promise in patients with DMO who fail to respond to laser treatment. ${ }^{28}$ Several clinical trials have already demonstrated greater benefit of combined anti-VEGF and laser on visual acuity than just laser treatment.111,129,130

\section{Conclusions}

Diabetic retinopathy, a leading cause of blindness and visual impairment in the working age population, remains a major unmet medical challenge. However, research efforts worldwide have led to the introduction of various novel therapeutic targets in diabetic retinopathy. These include specific inhibitors of aldose reductase, PKC $\beta 1 / 2$, anti-VEGF drugs (e.g., pegaptanib, bevacizumab, ranibizumab and VEGF trap), fenofibrate, renin-angiotensin system blockers, anti-inflammatory drugs, carbonic anhydrase inhibitors, and hyaluro nidase. These emerging drug therapies individually or most likely in combination with standard treatments (laser photocoagulation) may offer hope to diabetic patients by preventing and treating diabetic retinopathy.

\section{References}

1. King H, Aubert RE, Herman WH. Global burden of diabetes, 1995- 2025: prevalence, numerical estimates, and projections. Diabetes Care 1998;21:1414-31.

2. WHO. 201 Available from: http://www. who.int/diabetes/en/.

3. Wang Y, Fawzi A, Tan 0, et al. Retinal blood flow detection in diabetic patients by Doppler Fourier domain optical coherence tomography. Opt Express 2009;17: 
4061-73.

4. Wilkinson CP, Ferris FL, 3rd, Klein RE, et al. Proposed international clinical diabetic retinopathy and diabetic macular edema disease severity scales. Ophthalmology 2003;110:1677-82.

5. Hudson, C. The clinical features and classification of diabetic retinopathy. Ophthalmic Physiol Opt 1996;16:S43-48.

6. Durham JT, Herman IM. Microvascular Modifications in Diabetic Retinopathy. Curr Diab Rep 2011 May 25. [Epub ahead of print]

7. Resnikoff S, Pascolini, D, Etya'ale D, et al. Global data on visual impairment in the year 2002. Bull World Health Organ 2004; 82:844-51.

8. Klein R, Klein BE, Moss SE, et al. The Wisconsin epidemiologic study of diabetic retinopathy. III. Prevalence and risk of diabetic retinopathy when age at diagnosis is 30 or more years. Arch Ophthalmol 1984;102:527-32.

9. Klein R, Klein BE, Moss SE, et al. The Wisconsin epidemiologic study of diabetic retinopathy. II. Prevalence and risk of diabetic retinopathy when age at diagnosis is less than 30 years. Arch Ophthalmol 1984;102:520-6.

10. Davis MD, Fisher MR, Gangnon RE, et al. Risk factors for high-risk proliferative diabetic retinopathy and severe visual loss: Early Treatment Diabetic Retinopathy Study Report \#18. Invest Ophthalmol Vis Sci 1998;39:233-52.

11. The effect of intensive treatment of diabetes on the development and progression of long-term complications in insulin-dependent diabetes mellitus. The Diabetes Control and Complications Trial Research Group. N Engl J Med 1993;329:977-86.

12. Stratton IM, Kohner EM, Aldington SJ, et al. UKPDS 50: risk factors for incidence and progression of retinopathy in Type II diabetes over 6 years from diagnosis. Diabetologia 2001;44:156-63.

13. Diabetic Retinopathy Vitrectomy Study. Two-year course of visual acuity in severe proliferative diabetic retinopathy with conventional management. (Diabetic Retinopathy Vitrectomy Study Report Number 1. Ophthalmology 1985;92:492502.

14. Intensive blood-glucose control with sulphonylureas or insulin compared with conventional treatment and risk of complications in patients with type 2 diabetes (UKPDS 33). UK Prospective Diabetes Study (UKPDS) Group. Lancet 1998;352: 837-53.

15. Early worsening of diabetic retinopathy in the Diabetes Control and Complications Trial. Arch Ophthalmol 1998;116:874-86.
16. Klein R, Klein BE, Moss SE, et al. The Wisconsin Epidemiologic Study of diabetic retinopathy. XIV. Ten-year incidence and progression of diabetic retinopathy. Arch 0phthalmol 1994;112:1217-28.

17. Klein R, Knudtson MD, Lee KE, et al. The Wisconsin Epidemiologic Study of Diabetic Retinopathy: XXII the twentyfive-year progression of retinopathy in persons with type 1 diabetes. Ophthalmology 2008;115:1859-68.

18. Aiello LP, Gardner TW, King GL, et al. Diabetic retinopathy. Diabetes Care 1998;21:143-56.

19. Klein R, Klein BE, Moss SE, et al. The Wisconsin epidemiologic study of diabetic retinopathy. IV. Diabetic macular edema. Ophthalmology 1984;91:1464-74.

20. Klein R, Klein BE, Blood pressure control and diabetic retinopathy. Br J Ophthalmol 2002;86:365-67.

21. Tight blood pressure control and risk of macrovascular and microvascular complications in type 2 diabetes: UKPDS 38 . UK Prospective Diabetes Study Group. BMJ 1998;317:703-13.

22. Klein BE, Moss SE, Klein R. Is menarche associated with diabetic retinopathy? Diabetes Care 1990;13:1034-38.

23. Klein BE, Moss SE, Klein R. Effect of pregnancy on progression of diabetic retinopathy. Diabetes Care 1990;13:34-40.

24. Effect of pregnancy on microvascular complications in the diabetes control and complications trial. The Diabetes Control and Complications Trial Research Group. Diabetes Care 2000;23:1084-91.

25. Patel $\mathrm{S}$, Chen $\mathrm{H}$, Tinkham $\mathrm{NH}$, et al. Genetic susceptibility of diabetic retinopathy. Curr Diab Rep 2008;8:257-62.

26. Warpeha KM, Chakravarthy, U. Molecular genetics of microvascular disease in diabetic retinopathy. Eye (Lond) 2003;17: 305-11.

27. Chaturvedi N, Sjolie AK, Stephenson JM, et al. Effect of lisinopril on progression of retinopathy in normotensive people with type 1 diabetes. The EUCLID Study Group. EURODIAB Controlled Trial of Lisinopril in Insulin-Dependent Diabetes Mellitus. Lancet 1998;351:28-31.

28. Patel A, MacMahon S, Chalmers J, et al. Effects of a fixed combination of perindopril and indapamide on macrovascular and microvascular outcomes in patients with type 2 diabetes mellitus (the ADVANCE trial): a randomised controlled trial. Lancet 2007;370:829-40.

29. Lang, GE, Laser treatment of diabetic retinopathy. Dev Ophthalmol 2007;39:4868.

30. Lewis, H. The role of vitrectomy in the treatment of diabetic macular edema. Am J Ophthalmol 2001;131:123-5.
31. Tarr JM, Kaul K, Wolanska K, et al. Retinopathy in Diabetes, in Diabetes: An Old Disease A New Insight. Ahmed, S, Editor. Landes Bioscience; 2011.

32. Hohman TC, Nishimura C, Robison WG, Jr. Aldose reductase and polyol in cultured pericytes of human retinal capillaries. Exp Eye Res 1989;48:55-60.

33. Chung SS, Chung SK. Genetic analysis of aldose reductase in diabetic complications. Curr Med Chem 2003;10:1375-87.

34. Ludvigson MA, Sorenson RL. Immunohistochemical localization of aldose reductase. II. Rat eye and kidney. Diabetes 1980;29:450-9.

35. Engerman RL, Kern TS. Aldose reductase inhibition fails to prevent retinopathy in diabetic and galactosemic dogs. Diabetes 1993;42:820-5.

36. Robison WG, Jr., Nagata M, Laver N, et al. Diabetic-like retinopathy in rats prevented with an aldose reductase inhibitor. Invest Ophthalmol Vis Sci 1989;30:228592.

37. Szaflik JP, Majsterek I, Kowalski M, et al. Association between sorbitol dehydrogenase gene polymorphisms and type 2 diabetic retinopathy. Exp Eye Res 2008;86: 647-52.

38. Amano S, Yamagishi S, Koda Y, et al. Polymorphisms of sorbitol dehydrogenase (SDH) gene and susceptibility to diabetic retinopathy. Med Hypotheses 2003;60: 550-1.

39. Stitt AW. The role of advanced glycation in the pathogenesis of diabetic retinopathy. Exp Mol Pathol 2003;75:95-108.

40. Singh R, Barden A, Mori T, et al. Advanced glycation end-products: a review. Diabetologia 2001;44:129-46.

41. Yamagishi S. Role of advanced glycation end products (AGEs) and receptor for AGEs (RAGE) in vascular damage in diabetes. Exp Gerontol 2011;46:217-24.

42. Zong H, Ward M, Stitt AW. AGEs, RAGE, and Diabetic Retinopathy. Curr Diab Rep 2011 May 19. [Epub ahead of print.

43. Hammes HP, Martin S, Federlin K, et al. Aminoguanidine treatment inhibits the development of experimental diabetic retinopathy. Proc Natl Acad Sci USA 1991; 88:11555-8.

44. Thornalley PJ. Use of aminoguanidine (Pimagedine) to prevent the formation of advanced glycation endproducts. Arch Biochem Biophys 2003;419:31-40.

45. Shams N, Ianchulev T. Role of vascular endothelial growth factor in ocular angiogenesis. Ophthalmol Clin North Am 2006;19:335-44.

46. Bhisitkul RB. Vascular endothelial growth factor biology: clinical implications for ocular treatments. $\mathrm{Br} \mathrm{J}$ Ophthalmol 2006;90:1542-7. 
47. Caldwell RB, Bartoli M, Behzadian MA, et al. Vascular endothelial growth factor and diabetic retinopathy: role of oxidative stress. Curr Drug Targets 2005;6:511-24.

48. Kaul K, Hodgkinson A, Tarr JM, et al. Is inflammation a common retinal-renalnerve pathogenic link in diabetes? Curr Diabetes Rev 2010; 6: 294-303.

49. Chibber R, Ben-Mahmud BM, Chibber S, et al. Leukocytes in diabetic retinopathy. Curr Diabetes Rev 2007;3:3-14.

50. Grunwald JE, DuPont J, Riva CE. Retinal haemodynamics in patients with early diabetes mellitus. $\mathrm{Br} \mathrm{J}$ Ophthalmol 1996;80:327-31.

51. Kohner EM, Hamilton AM, Saunders SJ, et al. The retinal blood flow in diabetes. Diabetologia 1975;11:27-33.

52. MacKinnon JR, O'Brien C, Swa K, et al. Pulsatile ocular blood flow in untreated diabetic retinopathy. Acta Ophthalmol Scand 1997;75:661-4.

53. Bursell SE, Clermont AC, Kinsley BT, et al. Retinal blood flow changes in patients with insulin-dependent diabetes mellitus and no diabetic retinopathy. Invest Ophthalmol Vis Sci 1996;37:886-97.

54. Feke GT, Tagawa H, Yoshida A, et al. Retinal circulatory changes related to retinopathy progression in insulindependent diabetes mellitus. Ophthalmology 1985;92:1517-22.

55. Geyer 0, Neudorfer M, Snir T, et al. Pulsatile ocular blood flow in diabetic retinopathy. Acta Ophthalmol Scand 1999;77:522-5.

56. Findl 0, Dallinger S, Rami B, et al. Ocular haemodynamics and colour contrast sensitivity in patients with type 1 diabetes. Br J Ophthalmol 2000;84:493-8.

57. Simo R, Lecube A, Segura RM, et al. Free insulin growth factor-I and vascular endothelial growth factor in the vitreous fluid of patients with proliferative diabetic retinopathy. Am J Ophthalmol 2002;134: 376-82.

58. Grant M, Russell B, Fitzgerald C, et al. Insulin-like growth factors in vitreous. Studies in control and diabetic subjects with neovascularization. Diabetes 1986; 35:416-20.

59. Haurigot V, Villacampa P, Ribera A, et al. Increased intraocular insulin-like growth factor-I triggers blood-retinal barrier breakdown. J Biol Chem 2009;284:229619.

60. Danis RP, Bingaman DP. Insulin-like growth factor-1 retinal microangiopathy in the pig eye. Ophthalmology 1997;104:1661-9.

61. Adamis AP, Shima DT, Yeo KT, et al. Synthesis and secretion of vascular permeability factor/vascular endothelial growth factor by human retinal pigment epithelial cells. Biochem Biophys Res Commun 1993;193:631-8.

62. Wirostko B, Wong TY, Simo R. Vascular endothelial growth factor and diabetic complications. Prog Retin Eye Res 2008;27:608-21.

63. Adamis AP, Miller JW, Bernal MT, et al. Increased vascular endothelial growth factor levels in the vitreous of eyes with proliferative diabetic retinopathy. Am J Ophthalmol 1994;118:445-50.

64. Aiello LP, Avery RL, Arrigg PG, et al. Vascular endothelial growth factor in ocular fluid of patients with diabetic retinopathy and other retinal disorders. $\mathrm{N}$ Engl J Med 1994;331:1480-7.

65. Robinson GS, Pierce EA, Rook SL, et al. Oligodeoxynucleotides inhibit retinal neovascularization in a murine model of proliferative retinopathy. Proc Natl Acad Sci U S A 1996;93:4851-6.

66. Madsen-Bouterse SA, Kowluru RA. Oxidative stress and diabetic retinopathy: pathophysiological mechanisms and treatment perspectives. Rev Endocr Metab Disord 2008;9:315-27.

67. Kowluru RA, Chan PS. Oxidative stress and diabetic retinopathy. Exp Diabetes Res 2007;2007:43603-15.

68. Brownlee M. Biochemistry and molecular cell biology of diabetic complications. Nature 2001;414:813-20.

69. Brownlee M. The pathobiology of diabetic complications: a unifying mechanism. Diabetes 2005;54:1615-25.

70. Giacchetti G, Sechi LA, Rilli S, et al. The renin-angiotensin-aldosterone system, glucose metabolism and diabetes. Trends Endocrinol Metab 2005;16:120-6.

71. Sarlos S, Wilkinson-Berka JL. The reninangiotensin system and the developing retinal vasculature. Invest 0 phthalmol Vis Sci 2005;46:1069-77.

72. Tikellis C, Johnston CI, Forbes JM, et al. Identification of angiotensin converting enzyme 2 in the rodent retina. Curr Eye Res 2004;29:419-27.

73. Engler CB, Parving HH, Mathiesen ER, et al. Blood-retina barrier permeability in diabetes during acute ACE-inhibition. Acta Ophthalmol (Copenh) 1991;69:581-5.

74. Moravski CJ, Kelly DJ, Cooper ME, et al. Retinal neovascularization is prevented by blockade of the renin-angiotensin system. Hypertension 2000;36:1099-104.

75. Anil Kumar P. Bhanuprakash Reddy, G, Focus on molecules: aldose reductase. Exp Eye Res 2007;85:739-40.

76. Sun W, Oates PJ, Coutcher JB, et al. A selective aldose reductase inhibitor of a new structural class prevents or reverses early retinal abnormalities in experimental diabetic retinopathy. Diabetes 2006; $55: 2757-62$.
77. Kato N, Yashima S, Suzuki T, et al. Longterm treatment with fidarestat suppresses the development of diabetic retinopathy in STZ-induced diabetic rats. J Diabetes Complications 2003;17:374-79.

78. Donnelly R, Idris I, Forrester JV. Protein kinase $\mathrm{C}$ inhibition and diabetic retinopathy: a shot in the dark at translational research. Br J Ophthalmol 2004;88:14551.

79. Joy SV, Scates AC, Bearelly S, et al. Ruboxistaurin, a protein kinase $\mathrm{C}$ beta inhibitor, as an emerging treatment for diabetes microvascular complications. Ann Pharmacother 2005;39:1693-99.

80. The effect of ruboxistaurin on visual loss in patients with moderately severe to very severe nonproliferative diabetic retinopathy: initial results of the Protein Kinase C beta Inhibitor Diabetic Retinopathy Study (PKC-DRS) multicenter randomized clinical trial. Diabetes 2005;54:2188-97.

81. Effect of ruboxistaurin in patients with diabetic macular edema: thirty-month results of the randomized PKC-DMES clinical trial. Arch Ophthalmol 2007;125: 318-24.

82. Aiello LP, Davis MD, Girach A, et al. Effect of ruboxistaurin on visual loss in patients with diabetic retinopathy. Ophthalmology 2006;113:2221-30.

83. Joussen AM, Poulaki V, Mitsiades N, et al. Nonsteroidal anti-inflammatory drugs prevent early diabetic retinopathy via TNF-alpha suppression. FASEB J 2002; 16 : 438-40.

84. Kohner EM. Aspirin for diabetic retinopathy. BMJ 2003;327:1060-1.

85. Bergerhoff $\mathrm{K}$, Clar C, Richter B. Aspirin in diabetic retinopathy. A systematic review. Endocrinology and metabolism clinics of North America 2002;31:779-93.

86. Effects of aspirin treatment on diabetic retinopathy. ETDRS report number 8 . Early Treatment Diabetic Retinopathy Study Research Group. Ophthalmology 1991;98:757-65.

87. Gillies MC, Sutter FK, Simpson JM, et al., Intravitreal triamcinolone for refractory diabetic macular edema: two-year results of a double-masked, placebo-controlled, randomized clinical trial. Ophthalmology 2006;113:1533-8.

88. A randomized trial comparing intravitreal triamcinolone acetonide and focal/grid photocoagulation for diabetic macular edema. Ophthalmology 2008;115:1447-9.

89. Kuppermann BD, Blumenkranz MS, Haller JA, et al. Randomized controlled study of an intravitreous dexamethasone drug delivery system in patients with persistent macular edema. Arch Ophthalmol 2007;125:309-17.

90. Beck RW, Edwards AR, Aiello LP, et al. 
Three-year follow-up of a randomized trial comparing focal/grid photocoagulation and intravitreal triamcinolone for diabetic macular edema. Arch 0phthalmol 2009;127:245-51.

91. Kern TS, Miller CM, Du Y, et al. Topical administration of nepafenac inhibits diabetes-induced retinal microvascular disease and underlying abnormalities of retinal metabolism and physiology. Diabetes 2007;56:373-9.

92. Hariprasad SM, Callanan D, Gainey S, et al. Cystoid and diabetic macular edema treated with nepafenac $0.1 \%$. J Ocul Pharmacol Ther 2007;23:585-90.

93. Montero, JA, Ruiz-Moreno, JM, Intravitreal inserts of steroids to treat diabetic macular edema. Curr Diabetes Rev 2009;5:26-32.

94. Ottiger M, Thiel MA, Feige U, et al. Efficient intraocular penetration of topical anti-TNF-alpha single-chain antibody (ESBA105) to anterior and posterior segment without penetration enhancer. Invest Ophthalmol Vis Sci 2009;50:779-86.

95. Sfikakis PP, Grigoropoulos V, Emfietzoglou I, et al. Infliximab for diabetic macular edema refractory to laser photocoagulation: a randomized, doubleblind, placebo-controlled, crossover, 32week study. Diabetes Care 2010;33:15238.

96. Keech AC, Mitchell P, Summanen PA, et al. Effect of fenofibrate on the need for laser treatment for diabetic retinopathy (FIELD study): a randomised controlled trial. Lancet 2007;370:1687-97.

97. Chew EY, Ambrosius WT, Davis MD, et al. Effects of medical therapies on retinopathy progression in type 2 diabetes. $\mathrm{N}$ Engl J Med 2010;363:233-44.

98. Dodson PM. Management of diabetic retinopathy: could lipid-lowering be a worthwhile treatment modality? Eye 2009;23:997-03.

99. McCombe M, Lightman S, Eckland DJ, et al. Effect of a long-acting somatostatin analogue (BIM23014) on proliferative diabetic retinopathy: a pilot study. Eye 1991;5:569-75.

100. Mallet B, Vialettes B, Haroche S, et al. Stabilization of severe proliferative diabetic retinopathy by long-term treatment with SMS 201-995. Diabete \& metabolisme 1992;18:438-44.

101. Boehm B0, Lang GK, Jehle PM, et al. Octreotide reduces vitreous hemorrhage and loss of visual acuity risk in patients with high-risk proliferative diabetic retinopathy. Horm Metab Res 2001;33: 300-6.

102. Grant, MB, Mames, RN, Fitzgerald, C, et al., The efficacy of octreotide in the ther- apy of severe nonproliferative and early proliferative diabetic retinopathy: a randomized controlled study. Diabetes Care 2000; 23: 504-09.

103. Davis, MI, Wilson, SH, and Grant, MB, The therapeutic problem of proliferative diabetic retinopathy: targeting somatostatin receptors. Horm Metab Res 2001; 33: 295-99.

104. Bruns, C, Lewis, I, Briner, U, et al., S0M230: a novel somatostatin peptidomimetic with broad somatotropin release inhibiting factor (SRIF) receptor binding and a unique antisecretory profile. European journal of endocrinology / European Federation of Endocrine Societies 2002; 146: 707-16.

105. Cunningham, ET, Jr., Adamis, AP, Altaweel, M, et al., A phase II randomized double-masked trial of pegaptanib, an anti-vascular endothelial growth factor aptamer, for diabetic macular edema. Ophthalmology 2005; 112: 1747-57.

106. Nguyen, QD, Shah, SM, Heier, JS, et al., Primary End Point (Six Months) Results of the Ranibizumab for Edema of the mAcula in diabetes (READ-2) study. Ophthalmology 2009; 116: 2175-81.

107. Scott, IU, Edwards, AR, Beck, RW, et al., A phase II randomized clinical trial of intravitreal bevacizumab for diabetic macular edema. Ophthalmology 2007; 114:1860-67.

108. Mirshahi, A, Roohipoor, R, Lashay, A, et al., Bevacizumab-augmented retinal laser photocoagulation in proliferative diabetic retinopathy: a randomized doublemasked clinical trial. European journal of ophthalmology 2008; 18: 263-69.

109. Soheilian, M, Ramezani, A, Bijanzadeh, $\mathrm{B}$, et al., Intravitreal bevacizumab (avastin) injection alone or combined with triamcinolone versus macular photocoagulation as primary treatment of diabetic macular edema. Retina 2007; 27: 1187-95.

110. Soheilian, M, Ramezani, A, Obudi, A, et al., Randomized trial of intravitreal bevacizumab alone or combined with triamcinolone versus macular photocoagulation in diabetic macular edema. Ophthal mology 2009; 116: 1142-50.

111. Nguyen QD, Shah SM, Browning DJ, et al. A phase I study of intravitreal vascular endothelial growth factor trap-eye in patients with neovascular age-related macular degeneration. Ophthalmology 2009;116:2141-8.

112. Do DV, Schmidt-Erfurth U, Gonzalez VH, et al. The DA VINCI Study: Phase 2 Primary Results of VEGF Trap-Eye in Patients with Diabetic Macular Edema. Ophthalmology 2011. [Epub ahead of print].

113. Yang CM, Yeh PT, Yang $\mathrm{CH}$, et al. Bevacizumab pretreatment and long-acting gas infusion on vitreous clear-up after diabetic vitrectomy. Am J Ophthalmol 2008;146:211-7.

114. Yeh PT, Yang CM, Lin YC, et al. Bevacizumab pretreatment in vitrectomy with silicone oil for severe diabetic retinopathy. Retina 2009;29:768-74.

115. Saint-Geniez M, Maharaj AS, Walshe TE, et al. Endogenous VEGF is required for visual function: evidence for a survival role on muller cells and photoreceptors. PLoS One 2008;3:e3554.

116. Sjolie AK. Prospects for angiotensin receptor blockers in diabetic retinopathy. Diabetes Res Clin Pract 2007;76:S31-9.

117. Chaturvedi N, Porta M, Klein R, et al. Effect of candesartan on prevention (DIRECT-Prevent 1) and progression (DIRECT-Protect 1) of retinopathy in type 1 diabetes: randomised, placebo-controlled trials. Lancet 2008;372:1394-02.

118. Sjolie AK, Klein,R, Porta M, et al. Effect of candesartan on progression and regression of retinopathy in type 2 diabetes (DIRECT-Protect 2): a randomised placebo-controlled trial. Lancet 2008;372:138593.

119. Mauer M, Zinman B, Gardiner R, et al. Renal and retinal effects of enalapril and losartan in type 1 diabetes. $\mathrm{N}$ Engl $\mathrm{J}$ Med 2009;361:40-51.

120. Bursell SE, Clermont AC, Aiello LP, et al. High-dose vitamin E supplementation normalizes retinal blood flow and creatinine clearance in patients with type 1 diabetes. Diabetes Care 1999;22:1245-51.

121. Garcia-Medina JJ, Pinazo-Duran MD, Garcia-Medina M, et al. A 5-year follow-up of antioxidant supplementation in type 2 diabetic retinopathy. European journal of ophthalmology 2010. [Epub ahead of print]

122. Lonn E, Yusuf S, Hoogwerf B, et al. Effects of vitamin $\mathrm{E}$ on cardiovascular and microvascular outcomes in high-risk patients with diabetes: results of the HOPE study and MICRO-HOPE substudy. Diabetes Care 2002;25:1919-27.

123. Gao BB, Clermont A, Rook S, et al. Extracellular carbonic anhydrase mediates hemorrhagic retinal and cerebral vascular permeability through prekallikrein activation. Nat Med 2007;13: 181-8.

124. Trese MT, Enzymatic-assisted vitrectomy. Eye 2002;16:365-8.

125. Kuppermann BD, Thomas EL, de Smet MD, et al. Safety results of two phase III trials of an intravitreous injection of highly purified ovine hyaluronidase 
(Vitrase) for the management of vitreous hemorrhage. Am J Ophthalmol 2005;140: 585-97.

126. Kuppermann BD, Thomas EL, de Smet $\mathrm{MD}$, et al. Pooled efficacy results from two multinational randomized controlled clinical trials of a single intravitreous injection of highly purified ovine hyaluronidase (Vitrase) for the management of vitreous hemorrhage. Am J Ophthalmol 2005;140:573-84.

127. Sakuma, T, Tanaka, M, Mizota, A, et al.
Safety of in vivo pharmacologic vitreolysis with recombinant microplasmin in rabbit eyes. Invest Ophthalmol Vis Sci 2005;46: 3295-9.

128. Tsilimbaris MK, Pandeleondidis V, Panagiototglou T, et al. Intravitreal combination of triamcinolone acetonide and bevacizumab (Kenacort-Avastin) in diffuse diabetic macular edema. Semin Ophthalmol 2009;24:225-30.

129. Schmidinger G, Maar N, Bolz M, et al. Repeated intravitreal bevacizumab
(Avastin((R))) treatment of persistent new vessels in proliferative diabetic retinopathy after complete panretinal photocoagulation. Acta Ophthalmol 2011; 89:76-81.

130. Sun JK. Intravitreal Anti-VEGF Therapy with Prompt or Deferred Laser Compared with Steroid with Prompt Laser and Prompt Laser Alone for Treatment of Diabetic Macular Edema. Curr Diab Rep 2011. [Epub ahead of print] 